\title{
Is thirty-seven years sufficient for full return of the ant biota following restoration?
}

\author{
Jonathan D Majer ${ }^{1 *}$, Brian Heterick¹, Thomas Gohr ${ }^{1}$, Elliot Hughes ${ }^{1}$, Lewis Mounsher ${ }^{1}$ and Andrew Grigg ${ }^{2}$
}

\begin{abstract}
Introduction: An assessment of whether rehabilitated mine sites have resulted in natural or novel ecosystems requires monitoring over considerable periods of time or the use of space-for-time substitution (chronosequence) approaches.
\end{abstract}

Methods: To provide an assessment of ecosystem recovery in areas mined for bauxite in 1975, the ant fauna of one area planted with Eucalyptus resinifera, one seeded with mixed native species, one topsoiled but unrestored, and a forest reference was subjected to a 'long-term' study by sampling monthly and latterly annually between 1976 and 1989 using pitfall traps. These plots were resampled in 2012. A companion 'short-term' chronosequence study was performed in 1979 in 28 bauxite mines of various ages and restored by a range of different methods, plus three forest references. In order to examine the assertion that the observed differences between restored areas and forest references will lessen with time, sampling using comparable methods was repeated in 2012 in seven of the original plots, representing progressive advances in rehabilitation technology: planted pines; planted eastern states eucalypts; planted native eucalypts; planted eucalypts over seeded understorey; and planted eucalypts on fresh, double-stripped topsoil, plus two forest reference sites.

Results: Ant and other invertebrate richness in the long-term study was initially superior in the seeded plot, with little difference between the planted and unplanted plots. It was concluded that although composition of the ant fauna had converged on that of the forest over the 14-year period, differences still persisted. The 2012 resampling revealed that ant species richness and composition had deteriorated in the seeded plot, while values in the unplanted plot, which now supported naturally colonised trees and an understorey, had increased. Differences between all rehabilitated plots and forest still persisted.

As with the long-term study, the rate of fauna return and the type of ants present in the short-term study plots differed with the method of rehabilitation used, and, in 1979, no plots had converged on the forest in terms of the ant assemblage. By 2012 ant richness increased, and more so with each advance in rehabilitation technology, except for seeding, in which the understorey had collapsed. Double-stripping of topsoil resulted in the greatest improvements in ant species richness, although none of the areas had converged on the forest reference areas in terms of assemblage composition or ant functional group profiles. Furthermore, assemblage composition in the forest had changed over time, possibly due to reductions in rainfall, which further complicates rehabilitation objectives.

Conclusions: It is concluded that although rehabilitation can achieve its objective of restoring diversity, the original assemblage has still not been achieved after 37 years, suggesting that a degree of novelty has been introduced into these older-style rehabilitated areas. The company's current rehabilitation practices reflect multiple advances in their approach, lending optimism that current restoration may achieve something close to the original ecosystem, an outcome that can only be verified by extended studies like the one described here.

Keywords: Bauxite mining; Ant bioindicator; Long-term study; Chronosequence; Seeding; Planting; Succession

\footnotetext{
* Correspondence: J.Majer@curtin.edu.au

${ }^{1}$ Curtin Institute for Biodiversity and Climate, Curtin University, PO Box U1987,

Perth, WA 6845, Australia

Full list of author information is available at the end of the article
}

\section{国}

(c) 2013 Majer et al.; licensee Springer. This is an Open Access article distributed under the terms of the Creative Commons Attribution License (http://creativecommons.org/licenses/by/2.0), which permits unrestricted use, distribution, and reproduction in any medium, provided the original work is properly cited. 


\section{Introduction}

Alcoa of Australia Ltd. operates several bauxite mines in Western Australia and carries out an extensive rehabilitation program. Each year, approximately 600 ha of jarrah (Eucalyptus marginata) forest in southwest Western Australia are mined and then rehabilitated. The mining and rehabilitation process is described by Koch (2007). Briefly, areas to be mined are defined and the vegetation cleared. The topsoil is then removed (top $100 \mathrm{~mm}$ ) and respread on another area to be rehabilitated. The overburden is then scraped to a depth of $200-800 \mathrm{~mm}$ and stockpiled for later respreading. After this, the remaining caprocklayer is blasted and this, plus the underlying friable bauxite, is mined and taken away for processing. After ore extraction, pits are reshaped to integrate with the surrounding landscape and deep ripped to relieve mining-related compaction. Overburden and topsoil are returned, along with woody debris for fauna habitat, then areas are ripped again along the contour and seeded. Rehabilitation of Alcoa's Western Australian bauxite mines has been, and continues to be, an evolving process. Environmental requirements are the subject of State Government Agreements, which have become progressively more stringent as each new agreement for a mine site has been drawn up. For instance, the first Agreement in 1961 for the Jarrahdale No. 1 mine simply required the mined area to be left tidy, the 1972 Agreement for the next mine site required the company to reafforest the area and prevent soil erosion, and later agreements bound the company to continuous research and monitoring to gauge the effectiveness of restoration techniques. The current objective of Alcoa in regards to its WA bauxite mines is 'to establish a stable, self-regenerating jarrah forest ecosystem, planned to enhance or maintain water, timber, recreation, conservation and/or other nominated forest values' (Grant and Koch 2007). Inherent in this is the objective of restoring the species richness of the original forest ecosystem.

As a result, restoration has passed through a series of advances, starting from planting pines and other non-native species (1966), ripping the mine floor to allow better root penetration (1972), using fresh rather than stockpiled topsoil (late 1970s), direct seeding of native understorey species (1976), and double stripping of topsoil (1978). This involves separating the nutrient and seed-bearing uppermost layer from the subsoil and placing these back in the same order in order to preserve soil nutrients and the seed bank in the upper top soil layer. This has subsequently been followed by numerous other refinements, which continue to be developed and implemented (Grant and Koch 2007).

In addition to monitoring the performance of the vegetation following restoration, patterns of recolonisation of the vertebrate and invertebrate fauna have been monitored (Nichols and Nichols 2003). A prominent feature of this fauna monitoring program has been the use of ants; in fact the first example of using insects as bioindicators in Australia involved ants in Alcoa's bauxite mines (Majer 1977, 1983). This group of insects has proven to be a particularly useful bioindicator of plant structure and floristic composition and of other environmental factors and also tends to reflect the diversity and species composition of vegetation and many other invertebrate groups (Andersen and Majer 2004; Majer et al. 2007).

In the mid-1970s, two studies which centred on the use of ants were initiated. One was a 'long-term' case study which continuously monitored the succession of ants in a small number of rehabilitated plots from the point of topsoil replacement through to 14 years later. The other, carried out in the summer of 1978-1979, was a 'short-term' one-off investigation of 28 bauxite mines rehabilitated by a range of different methods and representing different ages. None of these areas had been rehabilitated according to the aims of Alcoa's current objectives, although it is constructive to look at their performance over an extended period.

It is still uncertain whether Alcoa's aim of restoring a jarrah forest-like ecosystem has been achieved. By their very nature, long-term studies of particular areas require considerable periods of time before such questions can be answered, while short-term chronosequence, or space-for -time substitution monitoring has inherent problems due to changes in rehabilitation technology, amongst other factors. For this reason, an opportunity has recently arisen to resurvey some of Alcoa's ant plots, 34-37 years after they were originally surveyed. All of the long-term study plots and five of the short-term study rehabilitated plots have been resurveyed in 2012 in order to see what changes have taken place over an extended period. The question we ask here is whether any of these areas have acquired an ant fauna that resembles that of the original jarrah forest or whether novel combinations of species have now colonised these areas.

Before describing the most recent study, it is necessary to review the findings of the original investigations.

\section{The long-term study}

This study was initiated in 1975 in three plots that were about to be rehabilitated and one forest reference. One plot was subsequently planted with non-native Eucalyptus resinifera [originally thought to be marri (Corymbia calophylla) and referred to as such in the original papers]; one was to be seeded with mixed native understorey species, along with planted native marri and non-native Eucalyptus resinifera; the third plot, of 1 ha $(100 \times 100 \mathrm{~m})$, was topsoiled but was not revegetated; a forest reference was also established. Sampling was initially performed weekly and later monthly for a 2-year period using single $6 \times 6$ grids of $18 \mathrm{~mm}$ internal diameter pitfall traps, spaced at $3 \mathrm{~m}$ intervals. Majer (1981) 
reported on the initial 2 years of sampling, concluding that seeding of mixed understorey allowed for the return of considerably more ant species than simply planting a tree monoculture, where ant species richness was only slightly greater than in the plot where no revegetation had been performed. These trends appeared to be reflected in the abundance and variety of other invertebrate groups.

Majer and Nichols (1998) continued with the sampling through to 14 years and found that, although ant species richness had increased in all mine plots, the findings from the first 2 years had been upheld, although in the last 6 years of sampling the richness of ants in the unrevegetated plot had started to move toward levels found in the other two mined plots as volunteer vegetation had naturally established in the area. Differences between the seeded and planted plots had also started to lessen, although ant assemblage composition in all mined plots still exhibited marked differences to that present in the forest reference.

\section{The short-term study}

In an attempt to provide rapid answers about the nature of ant succession in the rehabilitation, an intensive, shortterm, chronosequence study was performed in the summer of 1978-1979 (Majer et al. 1984). Twenty-eight bauxite mines and three forest references were surveyed by transects of pitfall traps, vegetation sweeping, tree beating, and both day and night hand collecting. Physical and botanical measurements were also taken. Using both species richness and Shannon's species diversity as descriptors, it was demonstrated by multiple regression analysis that ant return was positively associated with plant species richness and diversity, time since rehabilitation, percentage plant cover in certain strata, percentage litter cover, and the presence of coarse woody debris. Principal components analysis confirmed that these site variables also influenced the composition of the ant assemblages in the rehabilitated areas. Despite the oldest plots being 13 years old, no rehabilitated plots attained an ant assemblage that even closely resembled that of the forest references.

\section{Methods for 2012 study}

\section{The long-term study}

Attempts were made to locate the original three rehabilitated plots and the forest reference. The seeded plot was found, but marker posts were no longer present in the other areas, so new plots were established as close as possible to the original areas. Although physical and botanical measurements were not taken this time, plots were photographed for comparison with photos taken near the time of the 2-year and 14-year reports (Figures 1 and 2). Identical grids of $18 \mathrm{~mm}$ internal diameter pitfall traps were established and, as with the initial survey, traps were run for 7-day periods during summer (January) and winter (July). Traps were returned to the laboratory and sorted to species or morphospecies level using the Curtin University Ant Collection. The ant specimens from the original survey still existed, although identifications of these were converted to the current nomenclature used in the collection. Data for each plot were combined for the two seasons and summarised as ant abundance, ant species richness, Sorensen's index of similarity to forest reference, and functional group profile (sensu Andersen 1990, 1997).

\section{The short-term study}

Five of the original 28 rehabilitated plots were selected for resampling, with the selection designed to represent progressive advances in restoration procedures. Using the original plot numbers of Majer et al. (1984), these were plot 2 (planted with exotic Pinus pinaster in 1970; topsoil stockpiled), plot 10 (planted with exotic E. resinifera in 1970; topsoil stockpiled), plot 22 (mulched and planted with native marri and wandoo Eucalyptus wandoo in 1977; topsoil stockpiled), plot 20 (seeded native understorey with planted exotic E. resinifera and native marri in 1976; topsoil stockpiled), and plot 23 (double-stripped, fresh topsoil with planted native marri in 1975). In addition, two forest references were resampled; one at the Jarrahdale mine site and the other at Del Park. Although physical and botanical measurements were not taken this time, plots were photographed for comparison with photos taken near the time of the 1978-1979 survey (Figures 3 and 4).

As with the original survey, ants were sampled along $100 \mathrm{~m}$ transects using larger (42 $\mathrm{mm}$ internal diameter) pitfall traps, shrub sweeping, tree beating, and day-time hand collecting. This time, litter extraction was also performed using Tullgren funnels. The latter method was added to see if any litter-associated species had been missed by the other procedures and to offset the lack of night-time collecting (which is now administratively difficult to carry out). Sampling was carried out in April 2012 when conditions were still hot and dry and the litter sampling was repeated in winter (June) when the litter was moist. Ants were identified in the same way as in the long-term study, and the data were summarised as abundance, species richness, and functional group profile. In addition, for each plot the species were summarised as new to the area, lost from the original survey, or present in both surveys. Changes in the assemblage composition were assessed by principal components analysis, using ant presence/absence data derived from all sampling methods. We used the centred form of the Principal Components Analysis (PCA) (Chatfield and Collins 1980) to ordinate the samples. The software package CANOCO 4.5 (ter Braak and Šmilauer 2002) was used to perform the calculations. The results were visualised using the CanoDraw option of the CANOCO package. In the biplots, only the 


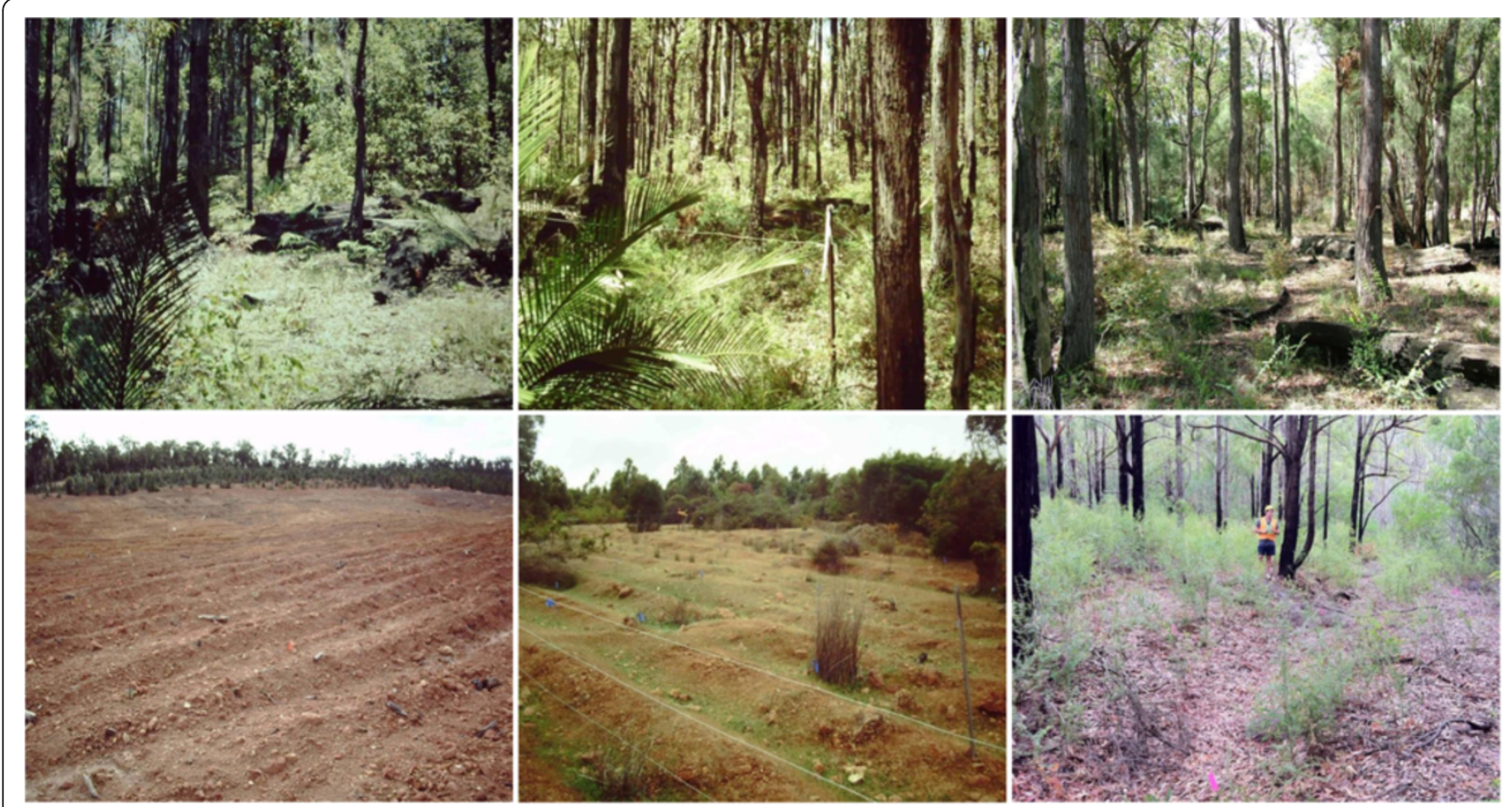

Figure 1 General views of the long-term study plots taken 2 years after (first column), 14 years after (second column), and 37 years after rehabilitation (third column). Forest control (top row), unplanted plot (second row).

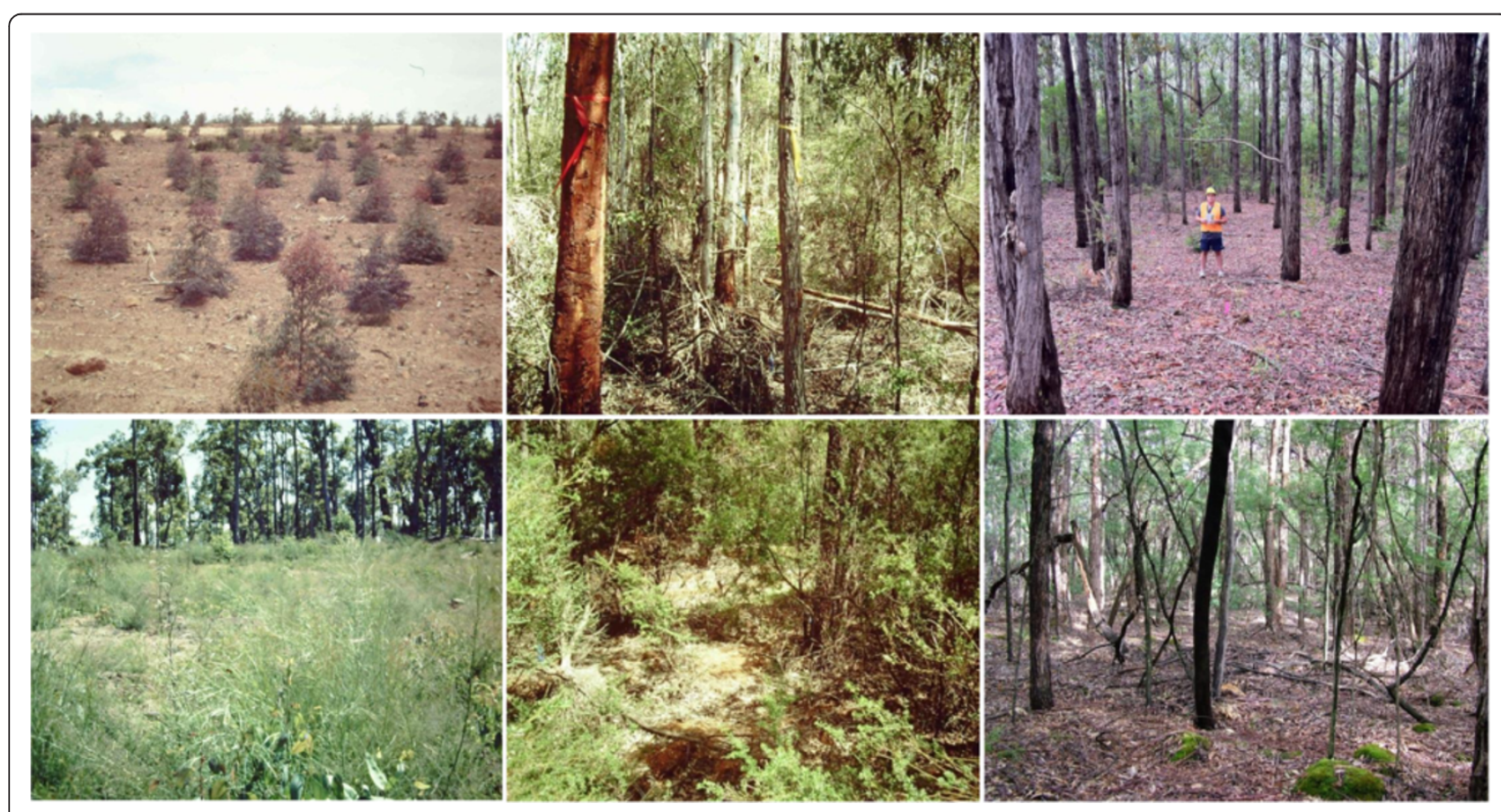

Figure 2 General views of the long-term study plots taken 2 years after (first column), 14 years after (second column), and 37 years after rehabilitation (third column). Planted plot (first row), seeded plot (second row). 


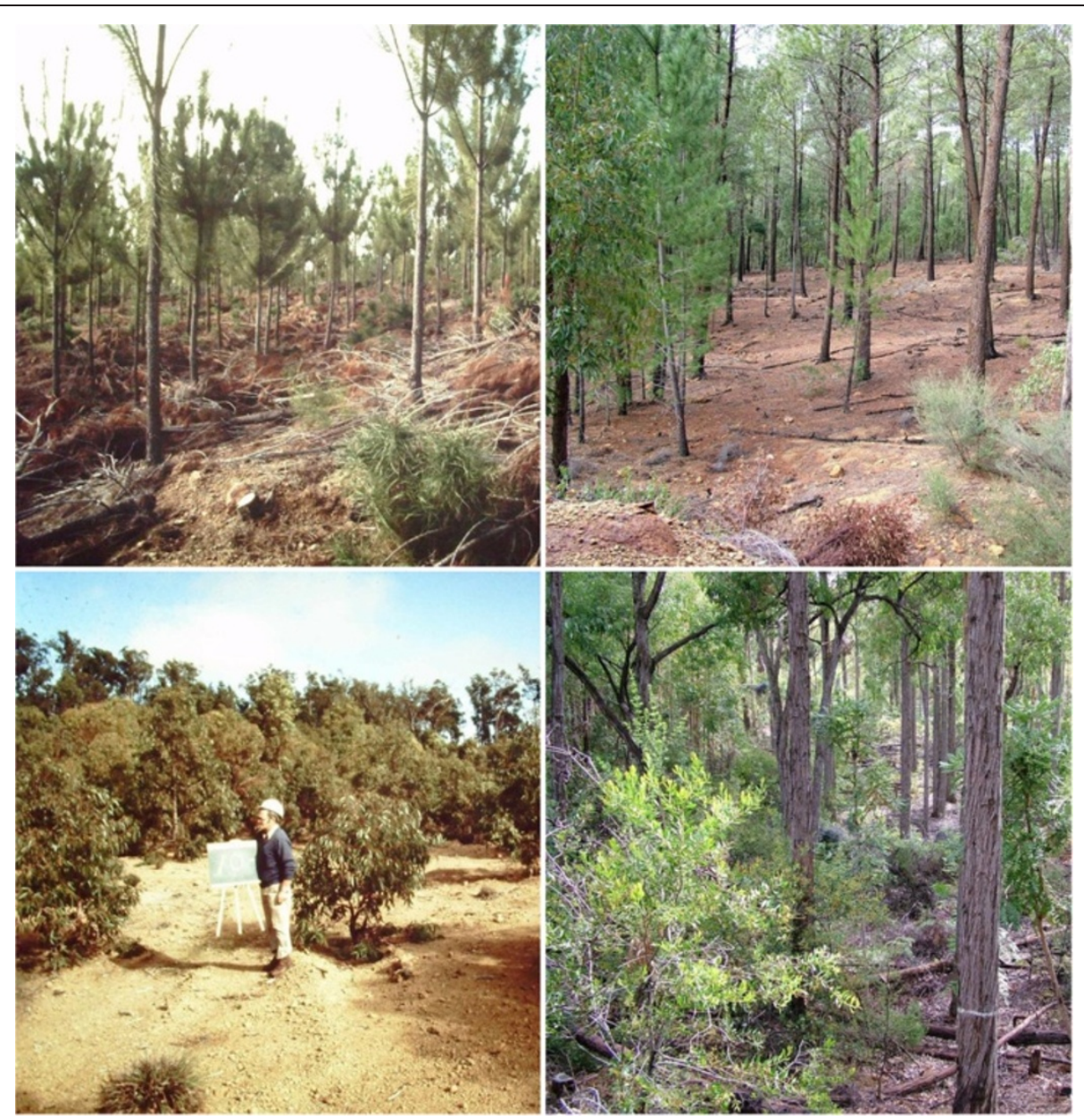

Figure 3 General views of the short-term study plots taken in 1979 and 2012. Pinus pinaster planted 1970 (top row), Eucalyptus resinifera planted 1970 (bottom row).

samples and selected species (those having high eigenvalues/factor loadings) were plotted.

\section{Results and discussion \\ The long-term study}

Inspection of the photographs of the plots shows that a shrub layer had started to develop in the unplanted plot by 14 years and a tree stratum was present by 37 years. Of particular note is that this area now has a shrub layer of the density (but not richness) found in the jarrah forest and also a dense litter layer (Figure 1). The planted plot had developed a dense tree stratum by 14 years, along with a dense understorey. However, by 37 years the understorey had almost completely disappeared, leaving a dense litter layer (Figure 2). The seeded plot immediately developed a shrub layer by 2 years and this was still present after 14 years. However, it had completely collapsed by 37 years, leaving a dense litter layer and stems of dead, short-lived understorey species such as Acacia spp. (Figure 2). Throughout the duration of the study the forest underwent fluctuations in shrub density, having experienced at least one forest fire, although it did not change appreciably in structure over the entire 37-year period (Figure 1).

The ant species found in the four plots are shown in Additional file 1. A total of 33 species were found in the three rehabilitated plots and 20 were found in the forest reference. A number of other species have previously been sampled in these plots but are no longer present, indicating the high degree of flux in species composition, a feature which has already been described in Majer and Nichols (1998). Overall ant abundance was slightly higher in the unplanted and planted plots than in the forest, but seeded plot values were considerably lower (Additional file 1). Species richness had increased to levels at or slightly above the forest reference in the unplanted and planted plots, indicating further improvements in invertebrate diversity in these plots (Figure 5a). However, unlike in the previous survey 23 years earlier, the seeded plot now supported the lowest richness of 


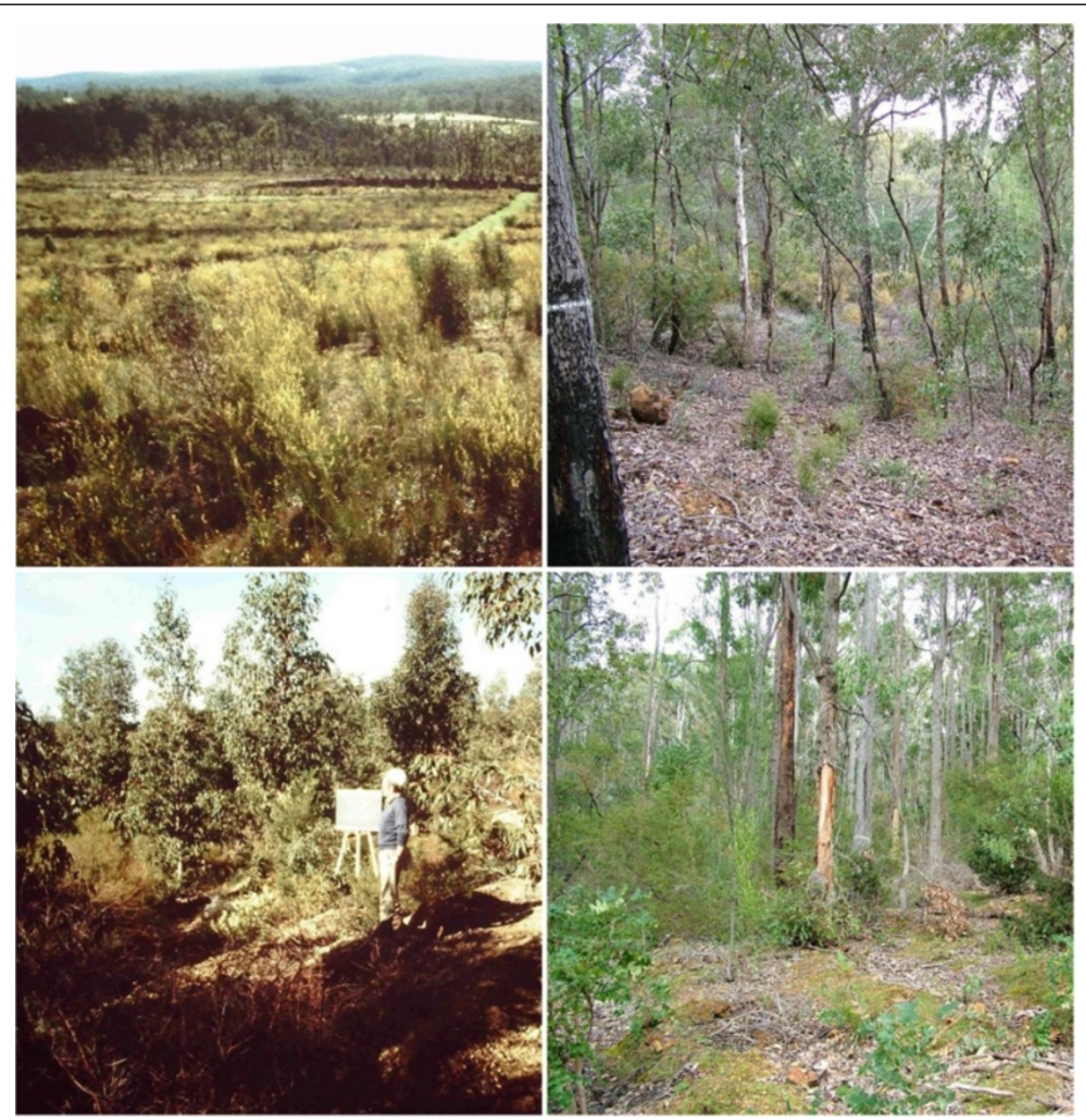

Figure 4 General views of the short-term study plots taken in 1979 and 2012. Corymbia calophylla and Eucalyptus wandoo planted and mulched 1977 (top row), Corymbia calophylla planted on double-stripped topsoil 1975 (bottom row). The seeded plot is not shown as it is the same plot as in the long-term study (Figure 2).

ants, with the level being half that found in the forest (Figure 5a). The ranking of rehabilitated plots was somewhat different in terms of similarity of assemblage composition with that present in the forest reference. In this case, the unplanted plot exhibited the greatest similarity to the forest, followed by the seeded plot and, finally, the planted plot (Figure 5b). Similarity to forest index values was relatively low in all plots, indicating that none of the plots had attained a totally forest-like ant assemblage.

The ant functional group profiles are shown in Figure 6 and are substantially different for each of the four plots. The unplanted plot is now dominated by opportunists, especially Rhytidoponera metallica and Rhytidoponera violacea. Other opportunists such as Ochetellus glaber group sp. JDM 15 and Tetramorium impressum are present in smaller numbers. Relatively large numbers of litter foraging species (e.g., Stigmacros spp.) and seed gatherers (Rhytidoponera inornata and Pheidole ampla perthensis) indicate a reasonably uniform understorey. The planted plot also contains a large number of opportunistic Rhytidoponera and Stigmacros, but the number and variety of subordinate Camponotus species may indicate lumpiness of ground texture, with many rocks and other cover under which these large ants can nest. In both this and the unplanted plot, the small myrmicine generalist Monomorium sordidum is abundant: this species is often prevalent in the years immediately following fire. The seeded plot has a quite different profile. Opportunists are lacking in this plot, but the presence of Pheidole ampla perthensis and Austromorium flavigaster suggests seeds are available for harvesting. Stigmacros sp. 115 and Monomorium leae are often found in damp, cool environments. The relatively large numbers of the solitary ponerine Pachycondyla (Trachymesopus) rufonigra are a feature of this plot. Finally, the forest reference has large numbers of dominant dolichoderines, which are totally lacking in the other three plots. However, with the exception of meat ants (Iridomyrmex purpureus), these are not species found in disturbed or open habitat. The ponerine 


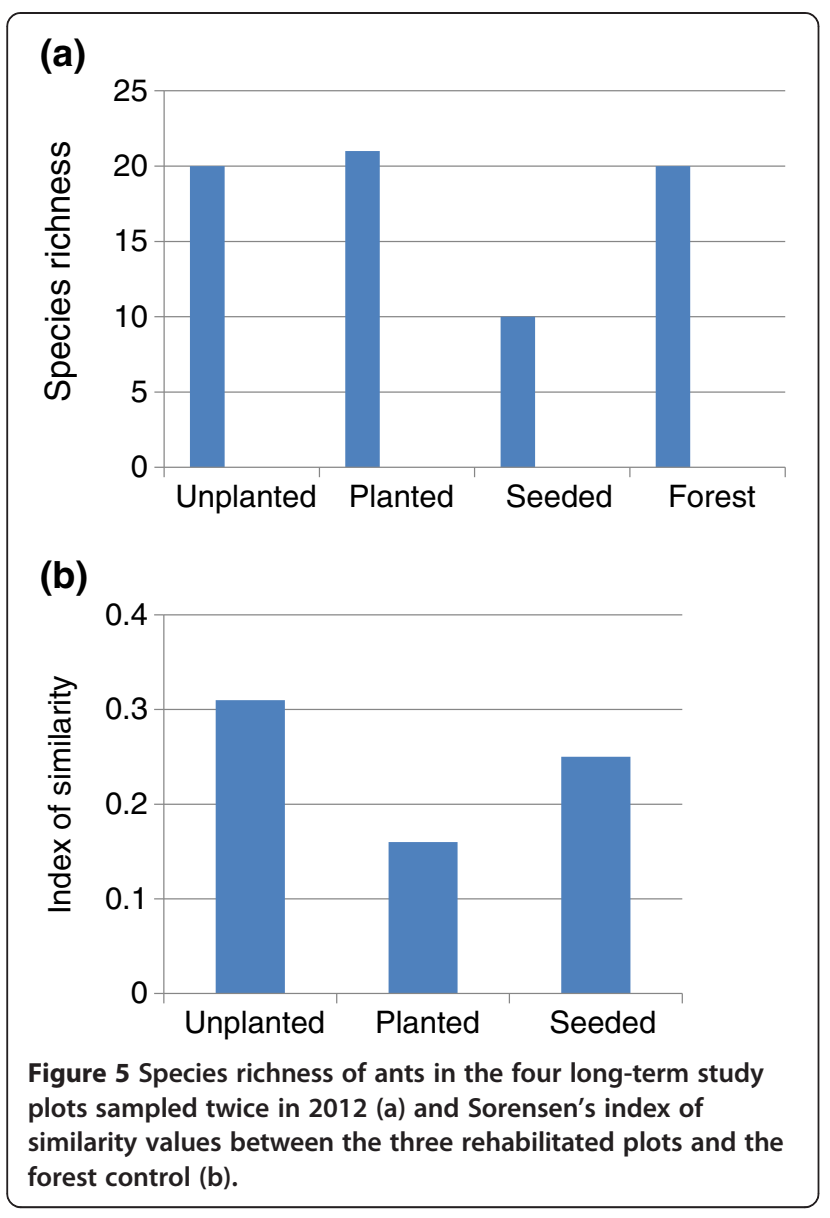

(a)

(b)

Figure 5 Species richness of ants in the four long-term study plots sampled twice in 2012 (a) and Sorensen's index of forest control (b) species Leptogenys neutralis is associated with relatively undisturbed forest, and Anonychomyrma itinerans perthensis is a typical sand dwelling species in open woodland. The presence of the introduced Argentine ant Linepithema humile in this woodland is surprising, as the other ant species in the plot are representative of healthy native forest. All in all, the large numbers of opportunistic species in the three rehabilitated plots indicate a continuing influence of disturbance, but the sites have not reached the point where they are dominated by thermophiles or small, highly abundant and competitive Iridomyrmex species.

\section{The short-term study}

The photographic record indicates that $P$. pinaster plot 2 had not changed in structure over the 34-year period, the main difference being in the size of the trees and the dense mat of pine needles beneath (Figure 3). The planted $E$. resinifera plot 10 differed from plot 2 in that a reasonably well developed understorey was present beneath the now large trees (Figure 3). A similar situation arose in the mulched and planted marri and wandoo plot 22 (Figure 4). Plot 20, with planted marri and E. resinifera and seeded understorey, is in the same area as used in the long-term study, so the reader is referred to Figure 2. Finally, the double-stripped topsoil plot 23, planted with marri, had an extremely diverse and well-developed understorey after 33 years, and the tree stratum was in good health (Figure 4). The forest references used in this study had both experienced forest fires during the course of the investigation, although they had not changed appreciably in structure. They generally resemble the situation in the long-term study reference, so their photographs are not shown here.

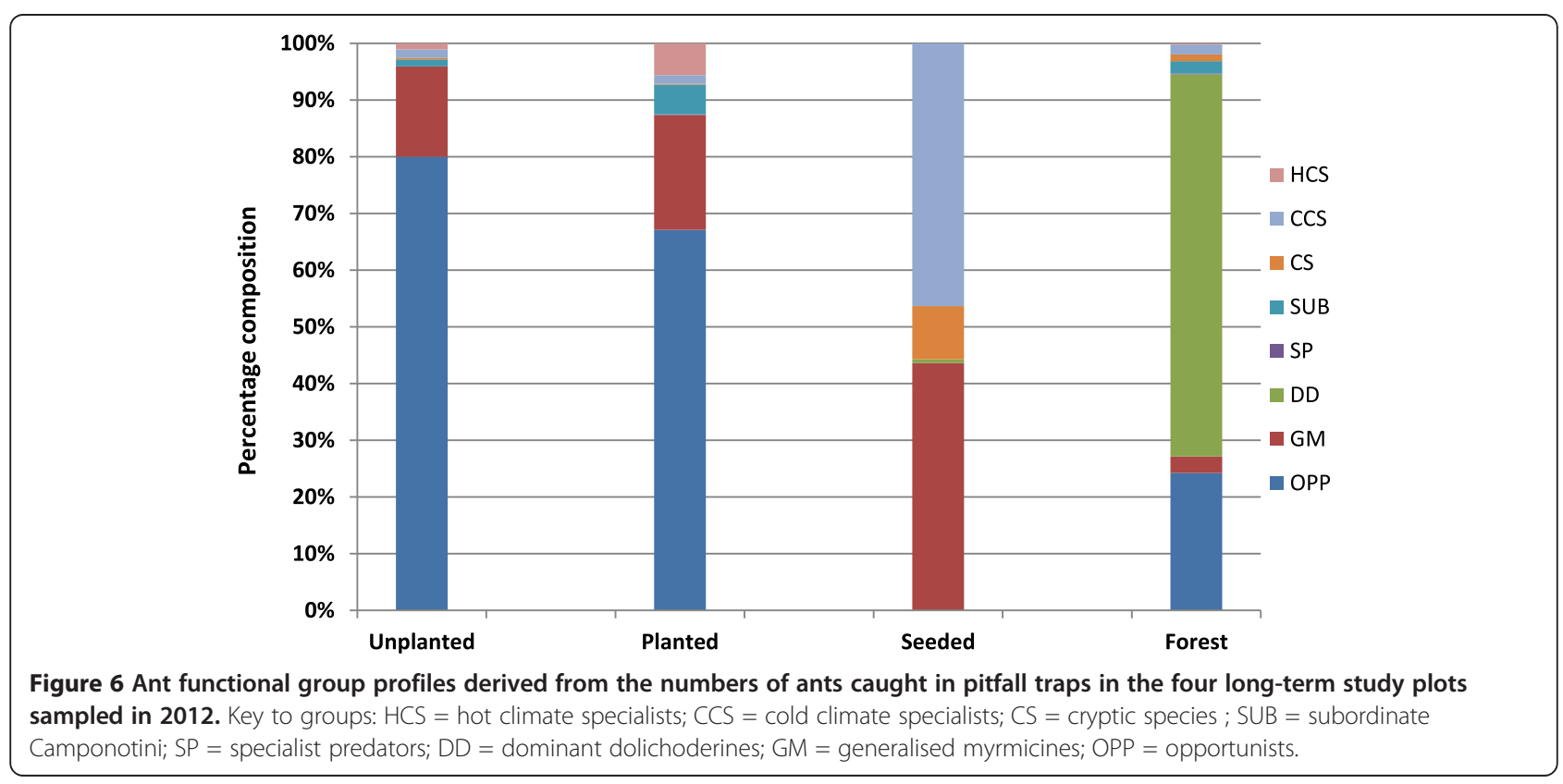


The ant species found in the seven plots are shown in Additional file 2, which also shows the equivalent values for the original survey. A degree of care should be exercised when comparing the two surveys as the sample months and methodologies are not identical. However, past experience informs us that as the procedures and sample months are equivalent, and replacement of one procedure by another provides a degree of compensation, this enables a valid comparison to be made between the two surveys. A total of 55 species were found in the five rehabilitated plots and 32 were found in the forest reference sites. Numbers of ants caught were much lower in all plots in 2012 than in the earlier survey (Additional file 2), which is probably attributable to differences in weather conditions during the trapping periods; there were no readily interpretable trends in abundance amongst the plots. Species richness increased beyond the 1978/9 levels in all rehabilitated plots, although the most dramatic increases were in the mulched and planted plot (22) and, particularly, in the double-stripped plot (23) (Figure 7). In both cases, richness far exceeded that measured in the forest references. The low values in the seeded plot, and the generally low increase between the two surveys, support the finding of the long-term study that this plot has regressed in relation to the other rehabilitated areas (actual richness values for this plot are not equal in the two studies due to slight differences in the sampling procedures used). Figure 8 shows the losses and gains in species between the original and current survey. These values may be inflated by the inclusion of rare species, but the trends are nevertheless noteworthy. In all cases there were appreciable losses and gains, indicating the replacement of pioneer species by those characteristic of more mature rehabilitation. However, once again, the greatest gains were in the mulched and planted plot (22) and in the double-stripped plot (23). It is also of importance to note that the forest references incurred a large number of losses, and an appreciable, but lesser, number of gains (Figure 8), highlighting the dynamic nature of the ant assemblage.

The ant functional group profiles for the short-term study plots are shown in Figure 9. The Pinus plot (plot 2) has a depauperate ant fauna consisting of almost $80 \%$ opportunists. This is an inhospitable environment for formicid species with more specialised traits. Typically, conifer plantations have little or no understorey, and few sources of nectar or honeydew for ants. What there is in the way of food tends to be monopolised by dominant ants and those that are adapted to a vagrant lifestyle. This habitat has shown little change in over 30 years. The plot planted with an eastern Australian eucalypt (Plot 10) has a more extensive fauna but is still dominated by opportunists and dominant Dolichoderinae. This is a much more open habitat, with several thermophilic Melophorus spp. present. Despite the eucalypts not being local, the apparently recent advent of several rare or cryptic species, including Colobostruma, indicates sufficient vegetative stratification to support specialist predators. The use of mulched local eucalypts (plot 22) has further increased the ant biodiversity and, in particular, the number of seed feeders and generalised myrmicines. The progress of the seeded plot (plot 23) seems to have stalled, with fewer thermophilic species compared with previously, although seed feeders are still in evidence. The double-stripped plot has the healthiest ant populations, with a diverse range of species, and many new additions in the most recent survey. Many of these are generalised myrmicines, perhaps reflecting a wide variety of seeds as well as carrion, nectar, and honeydew. The two reference sites, especially Del Park (although the original site could not be exactly located), show a worrying trend in terms of loss of species, especially ants such as solitary predators (Myrmecia spp.), and also Iridomyrmex conifer (the stick-nest ant) and Dolichoderus ypsilon.

The first and second axes of the principal components analysis ordination is shown in Figure 10, along with the ant species that make the greatest contribution to variance in the axes. For clarity, the diagram is shown twice, first with the species contributing to variance on axis 1 and second, the situation for axis 2 .

All of the rehabilitated plots sampled in 1978/9 fell on the negative part of axis 1 , while the resampled plots all fell on the positive part (Figure 10a). However, the degree of separation between old and new surveys differed greatly, with the $P$. pinaster plot 2 and seeded plot 20

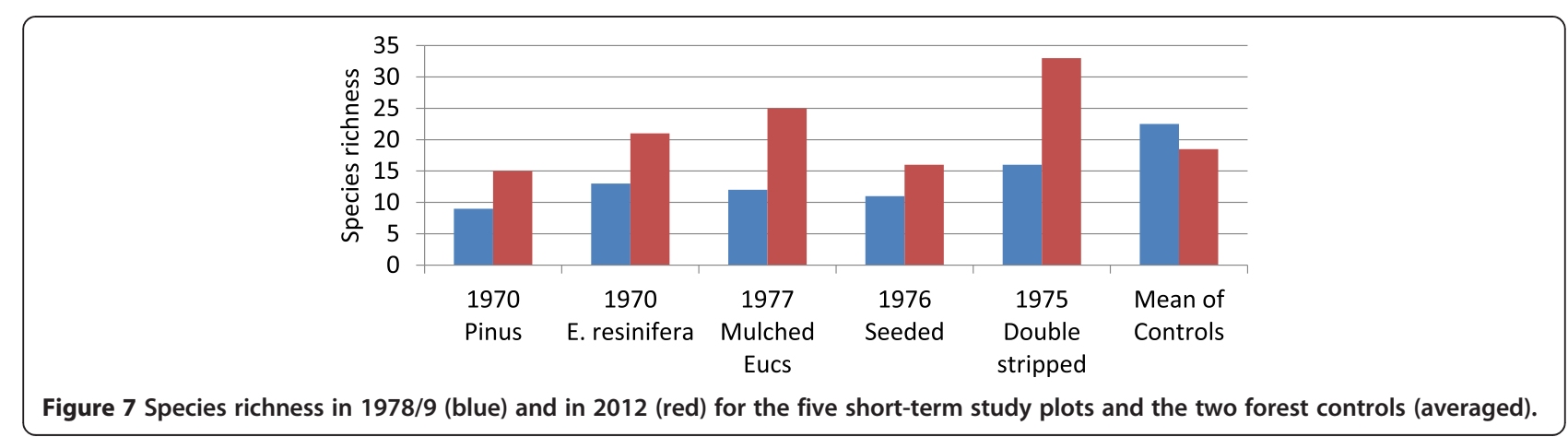




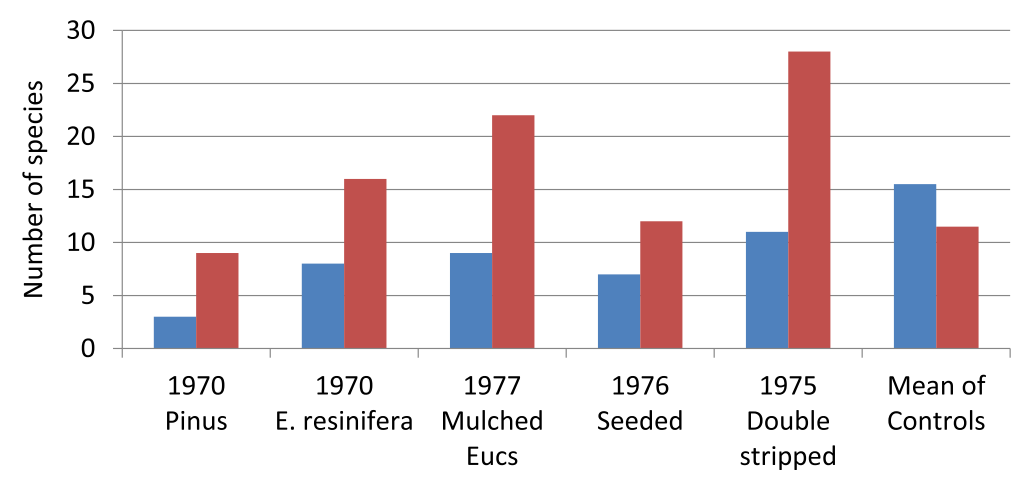

Figure 8 Losses (blue) and gains (red) in ant species between 1978/9 and 2012 for the five short-term study plots and the two forest controls (averaged).

showing the least change, followed by the planted plot 10 . The mulched marri/wandoo plot 22 showed considerable alteration, although the double-stripped plot 23 showed the greatest amount of change.

The 1978/9 plots were characterised by the presence of Iridomyrmex suchieri and Monomorium sydneyense, both of which are species that are typical of highly disturbed environments. A much greater number of species characterised the mature rehabilitation, including two species of Anonychomyrma, Austromorium flavigaster, Camponotus michaelseni, C. prostans, Colobostruma elliotti, Crematogaster queenslandica, Iridomyrmex chasei, I. mjobergi, Meranoplus ferrugineus, Monomorium sydneyense complex sp. JDM 101, two species of Pheidole, Podomyrma macrophthalma, two species of Stigmacros, Strumigenys quinquedentata, and Tapinoma sp. JDM 98, most of which are characteristic of shaded, forested conditions.
Although the old and new surveys of the forest references all fell near the centre of axis 1 , they both exhibited change from the positive to the negative part of axis 2 over the course of the study (Figure 10b). The forest of the original survey was characterised by Dolichoderus ypsilon, Iridomyrmex calvus, I. conifer, I. turbineus, Leptogenys neutralis, Myrmecia desertorum, and M. swalei, all but one of which were no longer present and most of which require cooler, moister conditions, characteristic of well-shaded forest. The only species to characterise the latest forest survey was Camponotus minimus, a widespread species which is tolerant of change.

\section{Both studies}

In discussing trends in the ant fauna, we reiterate that variations in ant assemblages tend to reliably reflect trends in other components of the biota (Andersen and Majer 2004; Majer et al. 2007), so the findings from this

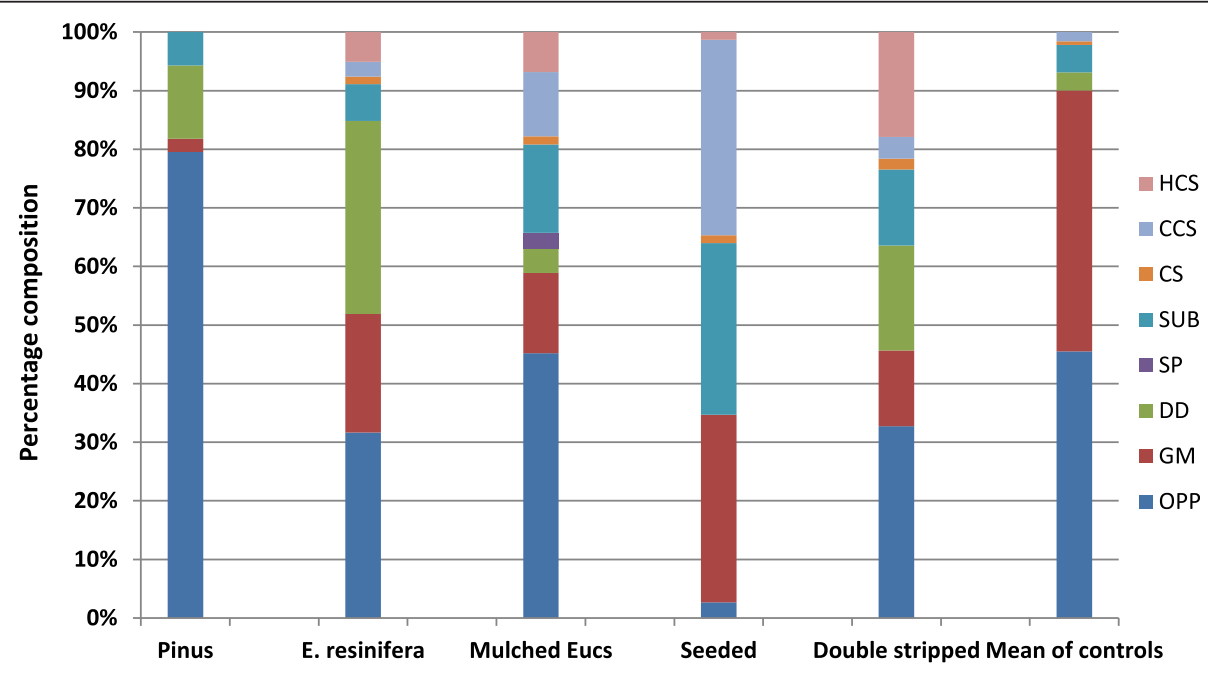

Figure 9 Ant functional group profiles derived from the numbers of ants caught in pitfall traps in the five short-term study plots and the two forest controls (averaged) sampled in 2012. Key to groups is shown in Figure 6. 

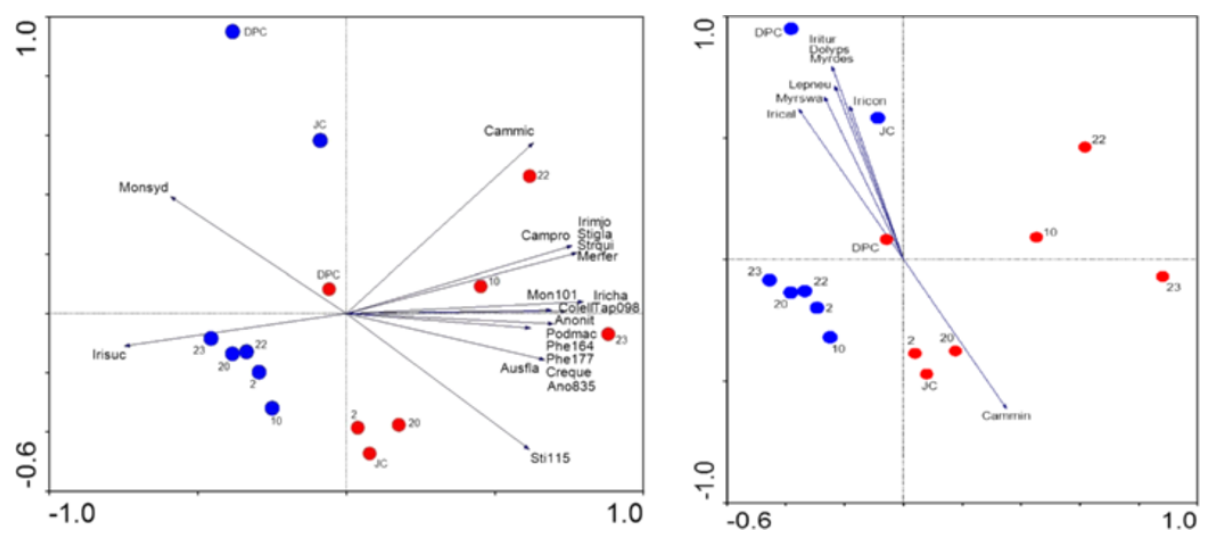

Figure 10 Principal components analysis ordination of the short-term study plots surveyed for ants in 1978/9 (blue) and in 2012 (red), showing the ant species that contribute most to variance of axis 1 (left) and axis 2 (right). Key to plots: DPC and JC = Del Park and Jarrahdale forest controls, 2 = planted Pinus pinaster, 10 = planted Eucalyptus resinifera, 22 = planted Corymbia calophylla and Eucalyptus wandoo with mulch, 20 = planted Corymbia calophylla and Eucalyptus resinifera with seeded understorey, and 23 = planted Corymbia calophylla on double-stripped topsoil. Key to ant names: Anonit = Anonychomyrma nitidiceps, Ano835 = Anonychomyrma sp. JDM 835, Ausfla = Austromorium flavigaster, Cammic = Camponotus michaelseni, Cammin = Camponotus minimus, Campro = Camponotus prostans, Colell = Colobostruma elliotti, Creque $=$ Crematogaster queenslandica, Dolyps $=$ Dolichoderus ypsilon, Irical = Iridomyrmex calvus, Iricha $=$ Iridomyrmex chasei, Iricon $=$ Iridomyrmex conifer, Irimjo = Iridomyrmex mjobergi, Irisuc = Iridomyrmex suchieri, Iritur = Iridomyrmex turbineus, Lepneu = Leptogenys neutralis, Merfer = Meranoplus ferrugineus, Monsyd = Monomorium sydneyense, Mon101 = Monomorium sydneyense complex sp. JDM 101, Myrdes = Myrmecia desertorum, Myrswa = Myrmecia swalei, Phe164 = Pheidole sp. JDM 164, Phe177 = Pheidole sp. nr. variabilis (JDM 177), Podmac = Podomyrma macrophthalma, Stigla = Stigmacros glauerti, Sti115 = Stigmacros JDM 115, Strqui = Strumigenys quinquedentata, Tap098= Tapinoma sp. JDM 98.

extended investigation into the performance of rehabilitation may be generalizable to many other components of the flora and fauna.

The first lesson from this longer look at the succession of ants is that conclusions reached after 2, or even 14 years, may not represent the outcome in the longer term. The high expectations for the seeded plot have not been upheld, with this plot performing poorly in terms of ant abundance, species richness and similarity of the ant assemblage to that of the forest. This is undoubtedly associated with the collapse of the understorey, a scenario that has recently been pointed out by Schneemann and McElhinney (2012) for densely seeded areas in New South Wales. Alcoa soon realised that the density of the seed mix that had been applied was far too great, so this is now no longer an issue due to the application of much lower densities of seed.

Secondly, the superior performance of the unplanted plot, at least in terms of ant species richness, suggests that there may be some merit in allowing a natural succession to take place, at least in small patches. Certainly, the unplanted plot has a well-developed understorey, as well as a reasonable density of trees. However, it should be remembered that this is a 1 ha area surrounded by areas that were rehabilitated by planting eucalypts, meaning that the area may have benefitted from nearby sources of propagules. Had a more extensive area been left in a non-revegetated state, the situation may have been different, as distances required for plant and animal recolonisation would be greater, a factor known to be an impediment (Whelan and Main 1979). However, the trends in this plot do suggest that the leaving of unrevegetated patches may have some merit by allowing certain species of plants and animals to recolonise without the influence of those plant species that have been artificially planted or seeded.

The trends observed in the short-term study highlight the benefits of the progressive improvements in rehabilitation technology since, with the exception of the over-seeded plot, the advances from pines to eucalypts, non-native to native eucalypts (possibly with mulching), and double-stripping of fresh topsoil have each contributed to improvements in diversity in the rehabilitated areas. The measured richness in some of the areas exceeded that in the forest references.

This raises the question of the environmental quality of the forested areas, at least those close to the bauxite mines of the northern jarrah forest. The trends in assemblage composition of the forest highlight a loss of species associated with good quality, shaded, moist forest towards species associated with disturbed conditions. At least four reasons can be advanced to explain this. One is that the forest references have been burnt at least once, and maybe twice, in the intervals between the surveys. Although this might be a contributory factor, it is not considered to be a major factor since ant assemblages are remarkably tolerant of fire (Andersen et al. 2009) and, in any case, the forest had also been burnt in the immediate period leading up to the time of the first survey. A second factor is that the fragmentation of the 
forest, and general proximity of the references to the mines, might have led to changes in the composition of the fauna. Edge effects are known to impact the composition of the invertebrate fauna, with impacts extending many metres from the disturbance (Didham 1997). Thirdly, invasive ants may have penetrated the area, with concomitant losses in native ant diversity. This is known to happen when Argentine ants (Linepithema humile) and Coastal brown ants (Pheidole megacephala) invade the area (Callan and Majer 2009). In this case though, despite $P$. megacephala having recently been found in the northern jarrah forest (J. Majer and B. Heterick, unpublished data), it was not found in any of the reference plots. L. humile was found in one of the forest plots (from the long-term study, Additional file 1), but its numbers were too small for it to exert any appreciable influence of the native ant fauna, at least for the present time. The final possibility relates to the $25 \%$ drop in annual rainfall that this part of Western Australia has experienced since the mid-1970s (IOCI Panel 2001). This translates into a drop in groundwater, a drying of the litter layer and general reduction in moisture (Reed et al. 2012). That many of the species that have been lost are types which require cool, moist, shaded conditions, supports this contention. Furthermore, this loss of species is consistent with our observations during the numerous ant surveys in the northern jarrah forest that we have been associated with. In almost all cases, the recent samples lack the rare or cryptic species that were readily found during the earlier surveys of the 1970s. Our study does not enable us to unravel these influences, but it does highlight that the composition of the native forest fauna is currently changing, which introduces a complicating factor to Alcoa's rehabilitation objective.

\section{Novel or natural?}

In terms of ant diversity, planting of eucalypts, and especially double-stripping of topsoil, has achieved diversity values in rehabilitated sites that are characteristic of the original forest. However, differences persist in the composition of the ant fauna. Furthermore, trajectories over the $37+$ years encompassed by this study, as depicted by the principal co-ordinates analysis, indicate that the ant assemblages in rehabilitated sites are not developing towards those of the forest reference sites. This suggests that convergence to an original forest fauna composition may occur over much longer periods than examined here or may not occur at all. The ecosystems developing after rehabilitation using the techniques described in this study may be regarded as 'novel' ecosystems (sensu Hobbs et al. 2006, 2009). Accepting ants as bioindicators of plant structure and floristic composition (Andersen and Majer 2004; Majer et al. 2007), these differences are likely to reflect persistent differences in plant species composition and structure in rehabilitated sites or other variables that recover over extended time frames such as the return of coarse woody debris (Koch et al. 2010). That said, with the exception of the seeded plot (which had been heavily over-seeded), the plots that had been planted with eucalypts and, especially, the one that had been double-stripped, continue to acquire new species and possess a fauna that has a reasonable resemblance to that of the original forest. This has continued to happen over $37+$ years, indicating that these examples of rehabilitation are self-sustaining, novel ecosystems, which provide no serious concern to the values of the jarrah forest in which they are embedded. To answer the ultimate question of natural or novel still requires monitoring over extended periods, as has been the case with the current study.

\section{Conclusions}

It is concluded that although rehabilitation can achieve its objective of restoring diversity, the original assemblage has still not been achieved after 37 years, suggesting that a degree of novelty has been introduced into these olderstyle rehabilitated areas. The company's current rehabilitation practices reflect multiple advances in their approach, lending optimism that current restoration may achieve something close to the original ecosystem, an outcome that can only be verified by extended studies like the one described here.

\section{Additional files}

Additional file 1: List of all ant species encountered in the 2012 sampling of the long-term study plots. Numbers are abundance in 36 pitfall traps. GPS co-ordinates for each plot are shown and the datum is WGS84.

Additional file 2: List of all ant species encountered in the 1978/79 and 2012 short-term study. GPS co-ordinates for each plot are shown and the datum is WGS84. Each column has been populated with pitfall trapping abundance data and other collection 'presence/absence' data. The totals are for pitfall trap catch only. Colours indicate whether a species had been gained in a particular plot (green), lost from that plot (orange) or retained over time (blue).

\section{Competing interests}

The authors declare that they have no competing interests, although much of this work was financially and materially supported by Alcoa of Australia Ltd. AG is employed in the environmental section of Alcoa of Australia Ltd and his mission is to ensure that the highest possible standards of restoration are achieved.

\section{Authors' contributions}

$\mathrm{JM}$ led this project from its inception until the present time and directed the most recent ant survey. TG, EH, and LM carried out the 2012 surveys and assisted with the data analysis. $\mathrm{BH}$ identified the ant material, provided input into the biology of the species, and assisted with manuscript preparation. AG assisted with plot location, provided information on rehabilitation procedures, and assisted with manuscript preparation. All authors read and approved the final manuscript. 


\section{Acknowledgements}

The authors thank Alcoa of Australia Ltd for funding and providing logistics for this work over the past 37 years and Curtin University for providing the facilities for enabling it to be carried out. Various Alcoa personnel, Curtin students and research assistants, too numerous to mention, have assisted over the years, and we extend our thanks to all of them. Prof Laco Mucina kindly assisted us with the principal components analysis.

\section{Author details}

'Curtin Institute for Biodiversity and Climate, Curtin University, PO Box U1987, Perth, WA 6845, Australia. ${ }^{2}$ Alcoa of Australia Ltd, PO Box 172, Pinjarra, WA 6208, Australia

Received: 11 February 2013 Accepted: 5 June 2013

Published: 4 July 2013

\section{References}

Andersen AN (1990) The use of ant communities to evaluate change in Australian terrestrial ecosystems: a review and a recipe. Proc Ecol Soc Aust 16:347-357

Andersen AN (1997) Functional groups and patterns of organization in North American ant communities: a comparison with Australia. J Biogeogr 24:433-460

Andersen AN, Majer JD (2004) Ants show the way down-under: invertebrates as bioindicators in land management. Front Ecol Environ 2:291-298

Andersen AN, Penman TD, Debas N, Houadria M (2009) Ant community responses to experimental fire and logging in a eucalypt forest of south-eastern Australia. For Ecol Manage 258:188-197

Callan SK, Majer JD (2009) Big-headed ants, Pheidole megacephala (Fabricius), invade urban bushland in Perth, Western Australia. Pac Conserv Biol 15:102-115

Chatfield C, Collins AJ (1980) Introduction to multivariate analysis. Chapman and Hall, London

Didham RK (1997) An overview of invertebrate responses to forest fragmentation. In: Watt AD, Stork NE, Hunter MD (eds) Forests and insects. Chapman and Hall, London, pp 303-320

Grant CJ, Koch J (2007) Decommissioning Western Australia's first bauxite mine: co-evolving vegetation restoration techniques and targets. Ecol Manage Restor 9:92-105

Hobbs RJ, Arico S, Aronson J, Baron JS, Bridgewater P, Cramer VA, Epstein PR, Ewel JJ, Klink CA, Lugo AE, Norton D, Ojima D, Richardson DM, Sanderson EW, Valladares F, Vila M, Zamora R, Zobel M (2006) Novel ecosystems: theoretical and management aspects of the new ecological world order. Glob Ecol Biogeogr 15:1-7

Hobbs RJ, Higgs E, Harris JA (2009) Novel ecosystems: implications for conservation and restoration. Trends Ecol Evol 24:599-605

IOCI Panel (2001) Towards understanding climate variability in south western Australia. Research reports on the second phase of the Indian Ocean Climate Initiative. Indian Ocean Climate Initiative Panel tech. rep. 2, Perth, Australia, http://www.ioci.org.au/publications/pdf/ IOCI_SPR.pdf

Koch JM (2007) Alcoa's mining and restoration process in south western Australia. Restor Ecol 15:S11-S46

Koch JM, Grigg AH, Gordon RK, Majer JD (2010) Arthropods in coarse woody debris in jarrah forest and rehabilitated bauxite mines in Western Australia. Ann For Sci 67:106. doi:10.1051/forest/2009087

Majer JD (1977) Preliminary survey of the epigaeic invertebrate fauna, with particular reference to ants, in areas of different land use at Dwellingup, Western Australia. For Ecol Manage 1:321-334

Majer JD (1981) The role of invertebrates in bauxite mine rehabilitation, W. A. Forests Department bulletin, no. 93. WA Forests Department, Perth

Majer JD (1983) Ants—useful bioindicators of minesite rehabilitation, land use and land conservation status. Environ Manage 7:375-383

Majer JD, Nichols OG (1998) Long-term recolonization patterns of ants in Western Australian rehabilitated bauxite mines, with reference to use as indicators of restoration success. J Appl Ecol 35:161-181

Majer JD, Day JE, Kabay ED, Perriman WS (1984) Recolonisation by ants in bauxite mines rehabilitated by a number of different methods. J Appl Ecol 21:355-375

Majer JD, Orabi G, Bisevac L (2007) Ants (Hymenoptera: Formicidae) pass the bioindicator scorecard. Myrmecol News 10:69-76
Nichols OG, Nichols FM (2003) Term trends in faunal recolonization after bauxite mining in the jarrah forest of southwestern Australia. Restor Ecol 11:261-272

Reed AJ, Barrett KL, Croton JT (2012) Future streamflows from the northern jarrah forest: learnings from the Wungong Catchment Trial. Western Australian Water Corporation report. Water Corporation, Leederville, Perth

Schneemann B, McElhinny C (2012) Shrubby today but not tomorrow? Structure, composition and regeneration dynamics of direct seeded revegetation. Ecol Manage Restor 13:282-289

Ter Braak CJF, Smilauer P (2002) CANOCO reference manual and CanoDraw for Windows user's guide. Software for canonical community ordination (version 4.5). , Biometris, Wageningen

Whelan RJ, Main AR (1979) Insect grazing and post-fire plant succession in southwest Australian woodland. Austral J Ecol 4:387-398

doi:10.1186/2192-1709-2-19

Cite this article as: Majer et al.: Is thirty-seven years sufficient for full return of the ant biota following restoration?. Ecological Processes 2013 2:19.

\section{Submit your manuscript to a SpringerOpen ${ }^{\odot}$ journal and benefit from:}

- Convenient online submission

- Rigorous peer review

- Immediate publication on acceptance

- Open access: articles freely available online

- High visibility within the field

- Retaining the copyright to your article

Submit your next manuscript at $>$ springeropen.com 